\title{
Behavior of Interfaces between Granular Soil and Structure: A State-of- the-art Review
}

\author{
Yao-Kun $\mathrm{Li}^{1}$, Xiao-Lei Han ${ }^{1,2,{ }^{*}}$, Jing $\mathrm{Ji}^{1,2}$, Dong-Long $\mathrm{Fu}^{1}$, Yan-Kun Qiu ${ }^{1}$, Bai-Cheng Dai ${ }^{1}$ and \\ Chao Lin ${ }^{1}$ \\ ${ }^{1}$ School of Civil Engineering and Transportation, South China University of Technology, Guangzhou, 510640, P.R. \\ China \\ ${ }^{2}$ State Key Laboratory of Subtropical Architecture Science, South China University of Technology, Guangzhou, 510640, \\ P.R. China
}

\begin{abstract}
A state-of-the-art review of the behavior of interfaces between granular materials and solid structural components is presented. The review includes both the experimental and theoretical researches on the interfaces between soils and steel, as well as those between soils and concrete. Development of constitutive relations of such interfaces is also summarized. Furthermore, numerical techniques, both the Finite Element Method and the Discrete Element Method (DEM), to simulate the interface behaviors are stated. Aspects for future development in this area are also included.
\end{abstract}

Keywords: Constitutive model, DEM, granular material, interface, structure.

\section{INTRODUCTION}

Interfaces between granular materials and structure are commonly seen in civil engineering. Soils are assemblies of small mineral particles with different radius and properties. Many kinds of structural components, such as raft, piles and retaining walls, are made from concrete or steel, which can be treated as solid continuum materials compared with soils. The interfaces between these two types of materials are of unique properties. The granular materials contain lots of voids, which make them easy to undergo large deformation when being loaded (both compression and shear). As a result, the widely accepted and commonly used Coulomb's Friction Model should be checked before applied to problems involving such interfaces.

Interfaces between granular soils and solid structural components exist everywhere. For instance, interfaces between piles and surrounding soil, between raft and ground soil, between retaining wall and soil behind it, and those between dams and neighboring rocks. The mechanical properties of such interfaces mainly include: bonding and slipping behaviors, strength and stiffness properties, the thickness of interfacial shearing layer, the main influential factors such as normal pressure, particle size, shearing velocity, materials types and their effects on the interface behavior. For the many unsolved problems, this paper summarizes and discusses researches on this subject all around the world, including the experiments and numerical simulation efforts, to present some conclusions and references for both researchers and engineers.

*Address correspondence to this author at the Room 303, Architectural Engineering Training Building, No.381, Wushan Road, Tianhe District, Guangzhou, 510641, P.R.China; E-mail: xlhan@ scut.edu.cn

\section{EXPERIMENTS ON BEHAVIOR OF SOIL- STRUCTURE INTERFACE}

\subsection{Experiments on Interfaces between Dry Sand and Metal}

At early times, the researches on the interface behaviors were focused on the friction resistance between dry sand and mild steel by experiments. Uesugi and Kishida (1986) [1] did the laboratory experiments on such friction properties and examined the significance of possible influential factors including surface roughness of the steel, 50 percent diameter of sand (mean diameter $D_{50}$ ), sand types, test type (simple shear and shear box) and uniformity coefficient of sand. It showed that steel roughness, $D_{50}$ of sand and sand type are the most significant factors to influence the interface friction resistance properties. Furthermore, the coefficient of friction can be correlated with the modified roundness of sand particles and the normalized roughness of sand-steel interfaces. Such conclusions were very helpful for us to evaluate the shaft friction and relative displacement between steel piles and surrounding sand soil. And the given curves between friction and shear displacement verified the correctness of the mechanical models presented by dozens of scholars, for instance the "perfectly plastic model".

Tejchman et al. (1995) [2] further investigated the effect of different boundary conditions of the whole system on the friction angle of the sand-steel interface and the localized shearing zone along it by experiments. Two different experimental apparatus were designed, which were plain strain apparatus and parallelly guided direct shear apparatus. The test results showed that the friction angle and the thickness of shear zone depend on the boundary conditions. The friction angle is bound by an upper limit approximately 
equal to the internal friction angle of sand and a lower limit of half the friction angle of quartz against quartz. The effects of multiple influential factors such as density of sand, steel roughness, the normal stress and so on, on the interface behaviors were also presented. Within the investigated range of stress level, the friction angle had little relation with the vertical stress. Then, a constitutive model based on the experimental results was developed.

Fakharian (1996) [3] deeply studied the monotonic and cyclic behavior of sand-steel interfaces by carrying a series of three dimensional tests. He developed a 3-D interface testing apparatus and did the experiments in direct shear type and simple shear type. The tests were also done with different boundary conditions, i.e. 2-D constant normal stress, 3-D constant normal stress and constant normal stiffness. The effects of normal stress, sand types, initial density of sand, interface roughness and roundness of sand particles on the monotonic interface behavior were investigated. Different from Tejchman's results, Fakharian thought that the normal stress influences the normalized shear stress of the interface. He stated that the ratio of shear stress and normal stress decreases with the increase of normal stress. The shear stress-displacement curve were totally different for interfaces with dense sand and loose sand. Specific peak shear stress can be identified for dense samples but not for the loose ones. Effects of the cyclic loading number and loading rate were also investigated in the research. Conclusions were found that the mobilized shear stress increases with the increasing number of loading cycles. And the envelope curves were similar with that in monotonic loading tests, i.e. the peak and residual shear stress were almost the same in two types of tests and the displacement required to mobilize the stress were also the same. As for loading rate, its influence on the shearing behavior of interface is negligible. Finally, Fakharian developed a constitutive model for the sand-steel interface based on plasticity theory.

In order to investigate the failure behavior of granularcontinuum interfaces, Frost (2002) [4] focused on two influential factors: roughness and hardness of continuum materials. A series of surface roughness and hardness measurements were conducted ahead of interface shear tests. The continuum materials were geomembranes, hardened steel, fibre-reinforced polymer, woods and rough finished concrete. Quantitative roughness and hardness index were presented for each of the selected material. On the basis of that, a series of interface shear tests were performed with all the continuum materials and two types of sands with different particles shapes: the Ottawa 20-30 sand with subrounded particles and the Valdosta blasting sand with angular particles. The tests were done with a direct shear apparatus. Frost pointed out that the friction angle of sand were the upper bound of the interface friction angle, for the shearing failure occurred in the shear zone near the interface even if the continuum material still stick with the granular materials. The test results showed that the peak and residual friction angle increase with the increase of surface roughness and decrease of surface hardness. And the two factors have a significant coupling effect, which means that the friction angle reaches a largest value with a largest surface roughness and a smallest surface hardness.
Porcino et al. (2003) [5] did the constant normal stiffness tests (CNS) on the interfaces between three different sands and four aluminium plates with different surface roughness. The normal stiffness was defined as the ratio of the increment of vertical stress and the vertical displacement. Both monotonic and cyclic shear tests were done in a direct shear box which provided the CNS condition. Main influential factors considered in the tests were constant normal stiffness, roughness of soil surface, mean diameters and roundness of sand grains, grain crushability, relative density of sand and the initial effective normal stress. Results for different materials were compared and they were similar to each other. It showed that the shear behavior of interface in CNS tests were related to the dilatant (rough interface) or contractive (smooth interface) behavior exhibited by interface in CNL (constant normal load) tests. And the change of the mobilized shear stress were caused by the evolution of normal stress; the friction angle of the interface remained unaltered.

\subsection{Experiments on Interfaces between Granular Materials and Concrete}

Taking into consideration sand-concrete interface, Desai et al. (1985) [6] designed a device for cyclic loading on large size interfaces between structural and geologic materials and rock joints. Both static and cyclic loading tests were done by this equipment. The test results were used to express shear stress as functions of normal stress, relative displacement, initial density and number of loading cycles. The shear stress versus relative displacement curves $\left(\tau-u_{\mathrm{r}}\right)$ were presented for different loading cycles $N$ and different amplitude of displacement. The envelopes of these curves were used for the analysis of the cyclic friction angle and the shear stiffness $K_{\mathrm{s}}$ (defined as the secant stiffness of the $\tau$ - $u$ curve). Finally, a modified Ramberg-Osgood model was proposed for the modeling of soil-concrete interface behavior.

$\mathrm{Hu}$ and $\mathrm{Pu}$ (2001) [7] did a series of direct shear tests on soil-structure interface using an improved apparatus with the digital camera to record particle movement at the interface. The sample was medium sand with a $D_{50}$ of $1 \mathrm{~mm}$. Two sand samples with different relative density and five steel plates with different roughness were included. A critical relative roughness $R_{\text {cr }}$ (the ratio of surface roughness to the mean diameter of sand particles) was found to be a critical factor for the shear behavior of the interface. When $R_{\mathrm{cr}}$ is greater than 0.01 , the strain localization occurs at the interface and a shear band in which large relative motions of particles happen forms. The thickness of the shear band was demonstrated to be $5 D_{50}$. The shear failure is accompanied by strain softening and strong normal dilatancy. The changing laws of peak and residual friction ratios of rough interfaces were also characterized.

Zhang and Zhang (2003) [8] developed an equipment for conducting static and cyclic shear test. Then series of experiments on the behavior of interface between gravel and rough steel plate under static and cyclic loading were conducted using this equipment $(2004)[9,10]$. The mean diameters $\left(D_{50}\right)$ of gravels were $7 \mathrm{~mm}$ and $10 \mathrm{~mm}$. An advanced photographic technology was used to record the state of particles at the interface and shear displacement of 
particles along the depth direction. So a clear understanding of the motion laws of particles in meso-scale was obtained. Based on the static and cyclic shear tests, they proposed five fundamental laws on the behavior of interface between coarse-grained soil and structure (2005) [11]. These five laws are: (1) Strength law: the shear stress of the interface has a linear relationship with the normal stress. (2) Shear law: the relationship between shear stress and shear strain at the interface is not a softening type. The tangent shear stiffness tends to be zero as the shear displacement increases, the stiffness of reloading and unloading in cyclic shearing tends to be the same with the increase of loading cycles. (3) Shear deformation law: a) the shear stress-relative displacement relations are not exact the same when the loading direction reverses, which is due to anisotropy of the interface after initial strong confinement effect. b) The shear displacement can be decomposed into shear deformation of the soil and sliding at the interface. (4) Compressive law: the vertical deformation at the interface in the shear process can be decomposed into permanent part and reversible part. The former is caused by the rearrangement of particles, which leads to the decrease of void; while the latter is caused by the rotation and relative motion of particles. (5) Evolution law: the meso-scale change in the shear zone is a process of partible breakage and shearing compression, which lead to irreversible dilatant volume strain; the corresponding macroscale phenomenon is the tendency to a stable value of shear stress and stiffness of the interface.

Hou et al. (2008) [12] developed a multi-functional 3-D shear test equipment, which realized different 3-D loading path in shear tests on the interface between coarse-grained soil and structure. The shear tests with different loading paths and boundary conditions in a single direction and torsional way were carried out. Feng (2012) [13] further conducted careful designed experiments with this test equipment. Different types of coarse-grained soil, different structural plates, different boundary conditions and loading conditions were included. The results of their tests showed deeply the laws of interface between coarse-grained soil and structure.

Peng et al. (2010) [14] reported simple shear test on the interface between coarse-grained soil and concrete. Zhu et al. (2011) [15] continued the study by focusing on the comparison of simple shear test and torsional shear test. A series of simple shear tests with different vertical pressure were done. Two different interfaces were considered, one without mud layer between concrete and soil (SC interface), the other with a $1 \mathrm{~mm}$ thick mud layer (SMC interface) to simulate some of the real interfaces, such as interfaces between soil and concrete piles. A conclusion was drawn that the simple shear test is more suitable for studying the shear displacement and deformation properties of interface in low stress state, while the torsional shear is suitable for testing the strength of the interface.

\subsection{Experiments on Behavior of Interface with Pore Fluid}

Desai (1997) [16] further stepped into the research on the behaviors of saturated interfaces under cyclic loading. He and his colleagues designed a cyclic multidegree of freedom
(CYMDOF-P) device to undertake such tests. Unlike other devices often used in previous studies, this device allowed for translational, normal and rotational motions, static and cyclic tests under direct and simple shear deformations, drained and undrained conditions, with the effect of porewater pressure. Then a serie of tests of clay-concrete and clay-steel interface behaviors were done. The results were compared with the available simple and direct shear tests, triaxial tests and field tests to verify the effectiveness of the device.

On the basis of the above results, Desai (2005) [17] studied on the saturated sand-concrete interface behavior. By a modified version of the above mentioned CYMDOF device, the leakage of sand through the interface during shear was prohibited. Different normal pressures and relative densities were considered as changing factors in the tests. Then one drained compression, three undrained one-way simple shear and three undrained cyclic (two-way) shear tests were done to calibrate parameters for an interfacial constitutive model based on disturbed state concept. The work done by Desai are of great importance for the progress of research on structure-soil behavior.

\subsection{Field Tests of Soil-concrete Interface Behavior}

Yang et al. (1999) [18] studied the anti-slide stability of interface between concrete raft and crushed stone cushion. A set of field tests on the friction ratio of concrete-crushed stone interface and concrete-coarse sand interface were done. The shear stress versus tangential displacement curves with different dry density of coarse particles and different vertical loads were got. Therefore, the corresponding friction ratio and shear stiffness of the interface were calculated. Qian (2002) [19] conducted anti-slide field tests of concrete structures on different natural ground, which brought out the shear strength of the interface between concrete raft and ground. He also suggested a standard field test method of the interface shear strength after analyzing different factors. Liu (2010) [20] thought that the replacing soft ground with a cushion layer of sand and gravel had the effect of increasing the horizontal resistant force between foundation and ground. Then the anti-slide shear tests with pre-cast concrete raft and field-cast concrete raft in several practical projects were done. A friction ratio of 0.55 to 0.60 was suggested for the anti-slide capacity of such interfaces. All these field test results can serve as good references to engineers.

As can be seen, the behavior of interface between granular material and structure has long been a popular topic in academic research. Different test data now available include indoor tests of direct shear, simple shear and torsional shear for macro and meso mechanical characteristics of the interface; and field test for anti-slide property of the interface. The main influential factors considered are normal stress, soil types, mean diameters of particles $\left(D_{50}\right)$, shape characteristics of particles (roundness and angularity), roughness of the interface, loading types (monotonic and cyclic), cyclic shearing rate and loading cycles, amplitude of shear displacement etc. The measured variables are peak shear strength, residual shear strength under different conditions, maximum friction ratio or normalized shear stress of the interface, shear stiffness etc. 
Although there exist strong demands for more advanced technologies like photography and fine measuring system in meso scale for deep research into the motion of particles and development of shearing zone at the interface, the multiple category of tests can still provide us with a general vision of the properties of granular material-structure interface. The consistency of all the test results got by different researches also make us certain about the credibility of all the mechanical laws showed by the experiments. This is quite beneficial for the development of an accurate and reliable constitutive model for the interface.

\section{NUMERICAL SIMULATION AND CONSTITUTIVE MODEL BASED ON CONTINUUM MECHANICS}

Following the experimental researches on the behaviors of interface between structure and granular materials, lots of efforts have been devoted to the numerical simulation of the interface. At early times, simulations were done by ways based on continuum mechanics, e.g. finite element method, finite differential method etc. Based on various shear test results and numerical modeling efforts, multiple constitutive models of the interfaces between structure and granular materials have been presented. These models include elastic, nonlinear elastic, plastic models, and different modified models based on traditional elasto-plastic concepts. Generally, the constitutive model can be divided into three main categories, which are element type, elastic or nonlinear elastic stress-strain relation, and elasto-plastic model. Here is a summary of these researches.

\subsection{Thin-layer Element}

At the beginning, the attention was mostly focused on the development of a special element in the finite element method. Goodman et al. (1968) [21] proposed a joint element for 2-D analysis; Zienkiewicz et al. (1970) [22] used the finite element formulation for the development of an interface element which was just like a solid element. Ghaboussi et al. (1973) [23] considered the relative motion between surrounding solid elements as an independent degree-of-freedom. Katona et al. (1976, 1981) [24, 25] developed an interface model which incorporates various deformation modes by adopting virtual work principle. Herrmann et al. (1978) [26] presented an algorithm for an interface element with constraint conditions to Goodman's element. The parameters in these elements are of no logical basis, which makes it necessary to perform parametric studies on selecting proper values to solve problems. What's more, they could only give satisfactory results of stick and slip modes for which normal stress keeps compressive, which were not enough for multiple conditions in practical problems.

In order to solve the above mentioned disadvantages, Desai et al. (1984) [27] proposed the thin-layer element as shown in Fig. (1). A solid element with a thin thickness was used to simulate the interface. Translational freedoms were considered at the interface nodes. Equations for the proposed thin-layer element were first presented, which can be linear elastic, non-linear elastic and elasto-plastic. Then by conducting a parametric study, Desai suggested that the element thickness be in a range of 0.01 to 0.1 of the surrounding solid element dimension. Various deformation modes were incorporated and a number of problems with displacement, mixed and hybrid finite element procedures were implemented. Finally six examples were tested for the validity of the proposed thin-layer element in both two and three dimensional problems.
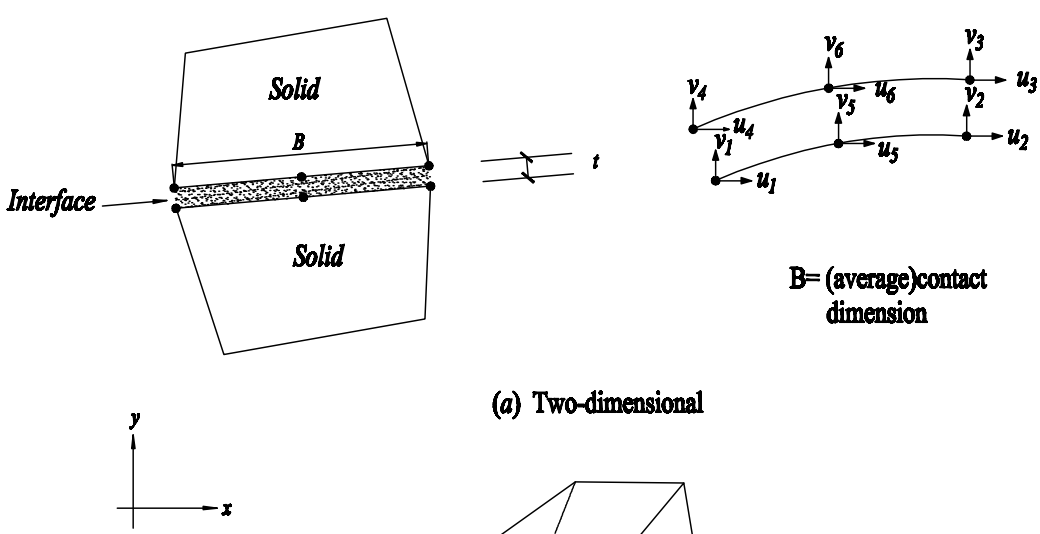

(a) Two-dimensional

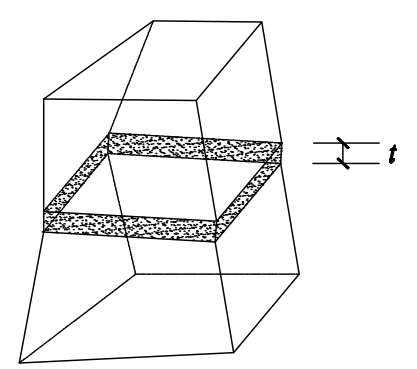

(b) Three-dimensional

Fig. (1). Thin-layer interface element [27]. 
Zaman et al. (1984) [28] adopted the thin-layer element to model dynamic soil-structure interaction. The results were compared to a model structure tested in the field. The influence of the interface behavior on displacements, velocities and accelerations were delineated. But the complexity of the dynamic problems made further studies necessary for a more clear understanding of the influential laws.

Sharma and Desai (1992) [29] further displayed the necessary matrix equations for the realization of the thinlayer element. Then a detailed parametric study was done to show that the zero-thickness element of Goodman may not provide satisfactory results for normal stress and displacement, but it could be included as a convergence result of the thin-layer element. Then predictions of thinlayer element and finite element with hierarchical plasticity model matched with each other quite well, which can be a verification for the effectiveness of the thin-layer element. A detailed parametric study also presented an empirical criteria for the selection of a proper thickness of the thin-layer element zone, but further studies were necessary for a closed-form criteria based on physical and theoretical considerations that would include main influential factors.

\subsection{Non-linear Elastic Model}

A non-linear model was proposed by Clough and Duncan which was widely used in numerical analysis (1971) [30]. The hyperbolic-type relationship of the shear stress and relative tangential displacement was obtained from the interface direct shear test. But it was proved to be not able to predict the strain softening and normal dilatancy often observed at the interface.

Desai et al. (1985) [6] developed a test equipment for static and cyclic shear test on sand-concrete interfaces. Then a series of cyclic and static tests were performed using this equipment. The study focused mainly on influential factors of normal stress, relative density of sand, amplitude of displacement, amplitude of shear stress and number of loading cycles. The static behavior of interface was described with traditional Mohr-Coulomb strength envelope. But the envelope of $\tau / \sigma_{\mathrm{n}}$ curves in cyclic loading tests were not the same with conventional Mohr-Coulomb criteria. The slope of the envelope was defined as mobilized stress ratio $\left(\tau / \sigma_{\mathrm{n}}\right)$. Such displacement controlled test results were mainly used to find appropriate parameters for the Modified Ramberg-Osgood Model that proposed by Desai and his colleagues. The nonlinear elastic relation was proved to work well in predicting the behavior of sand-concrete interface, for the prediction not only matched well with the test results for finding parameters, but also with the results of another set of load-controlled cyclic tests. The research also included the verification of the finite element analysis of the cyclic test using the thin-layer element proposed by Desai et al. (1984) [27]. Both the element-based method and the non-linear elastic model of MRO were proved to be effective, but should be tested and verified on interfaces other than sandconcrete ones before being adopted in design and analysis. What's more, a more precise elasto-plastic model should be developed if improved measurements of volume and density changes and stresses at the interface were possible.

The normal behavior of interface was always being neglected in the past, leading to no model to fully integrate mathematical, experimental and verification aspects and various modes of deformation of interfaces subjected to cyclic normal and shear load. A further research had been done by Desai and Nagaraj (1988) [31] on testing the normal and shear behavior of sand-concrete interface, and on the development of a constitutive model which includes both normal and shear properties of interface. The common

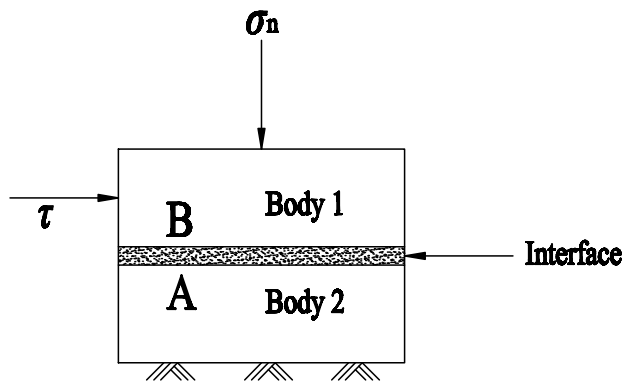

(a)

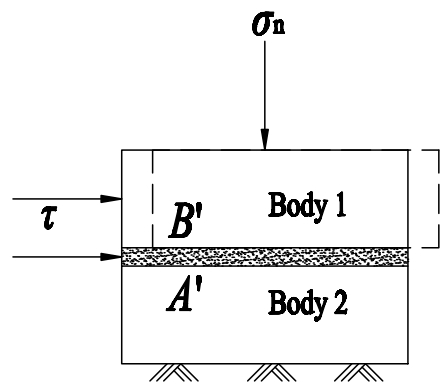

(b)

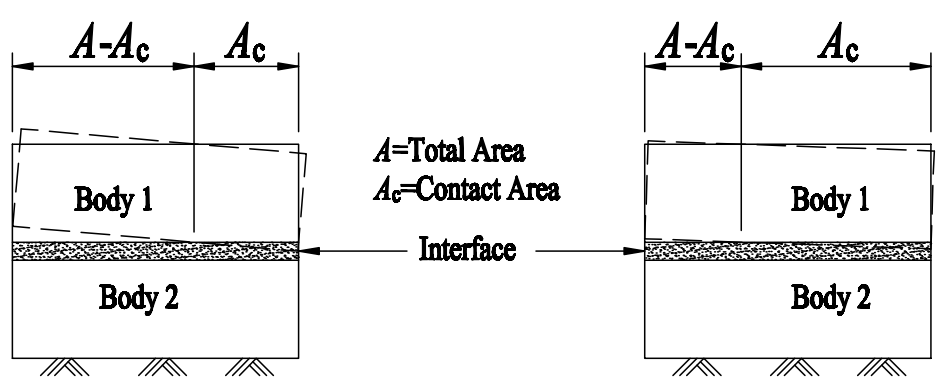

(c)

Fig. (2). Schematic of modes of deformation at interface (two-dimensional): (a) Stick or No Slip; (b)Slip or Sliding; (c) Debonding; (d) Rebonding [31]. 
modes of deformation at the interface are shown in Fig. (2). Two series of tests were done. Only cyclic normal stress under load controlled condition with the form of $\sigma_{\mathrm{n}}=\sigma_{0}+\sigma_{\mathrm{a}} \cdot \sin (\omega t)$, was applied in the first series. Simultaneous cycles of both normal and shear loadings were involved in the second series. The normal stress was still of the first form, while the shear loading was applied in sinusoidal form of shear displacement. The testing plan is shown in Fig. (3). Then the non-linear elastic constitutive model consisting of both normal and shear behaviors was developed according to the test results. The normal behavior was considered to be composed of (see Fig. (4): 1) Virgin loading; 2) unloading; 3) reloading; 4) tensile condition; 5) partial debonding; and 6) rebonding. The shear behavior was described using a MRO Model as previously stated, and was considered to be uncoupled with the normal behavior. As verifications, the proposed model was then used for prediction of the test results and was realized in a dynamic finite element procedure. The model provided an improved methodology for developing realistic constitutive models for the interface behavior. But the equations for both the normal and shear behaviors were much too complicated, which makes it difficult to be used in practical engineering design and analysis.

\subsection{Elasto-Plastic Model}

Chen et al. (1987) [32] adopted the nonassociated plasticity theory to develop a nonlocal constitutive model for the sand-concrete interface. The model was only suitable for small-strain problems, for its assumptions of no-slip at the interface and small deformation of soil. A very simple onedimensional problem was solved as a verification. Though the localized shear zone and the deformation fields in the vicinity of the interface could be predicted well, further experimental data were required to verify the computational algorithm.

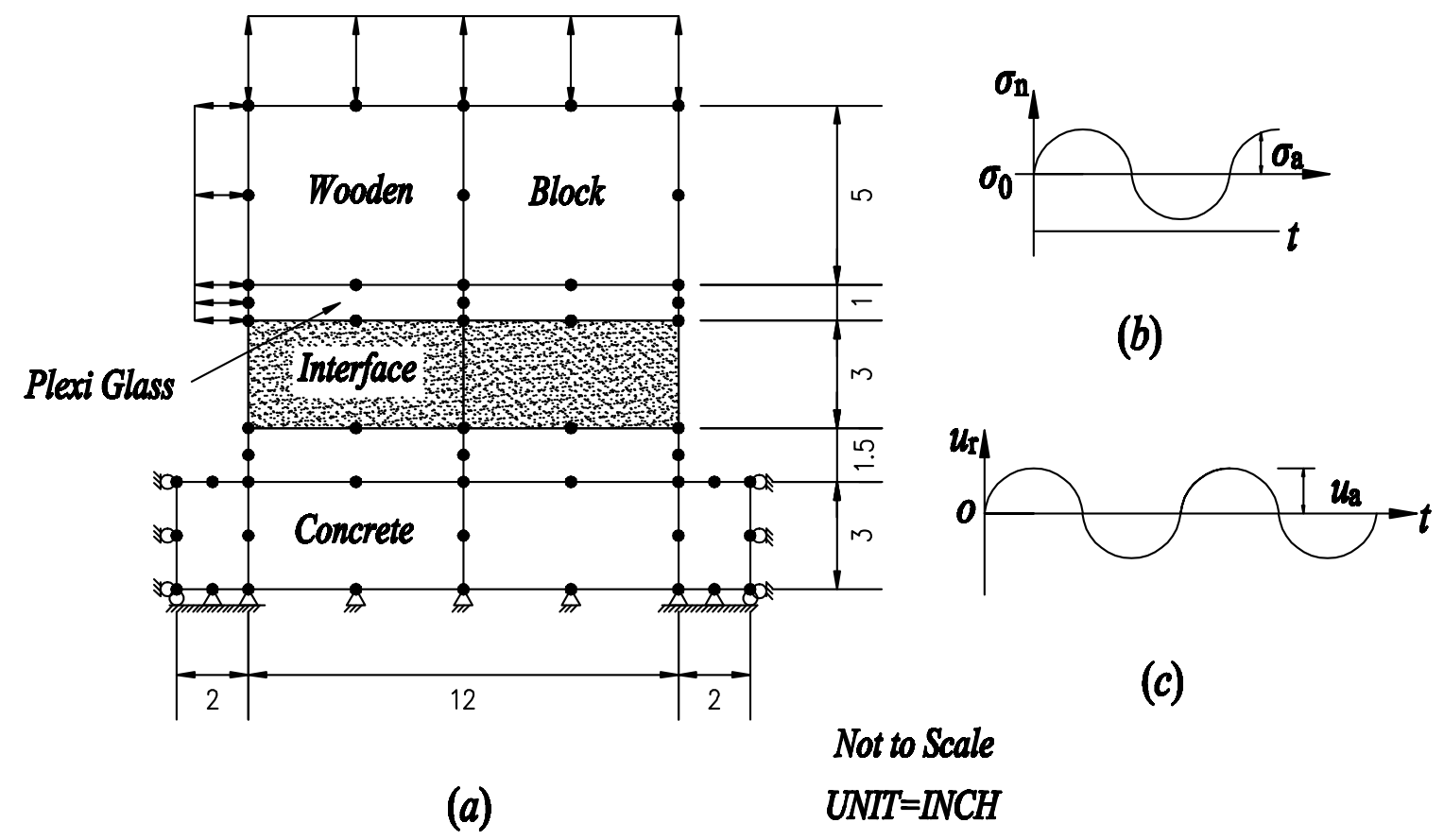

Fig. (3). Finite element mesh of test set-up [31].
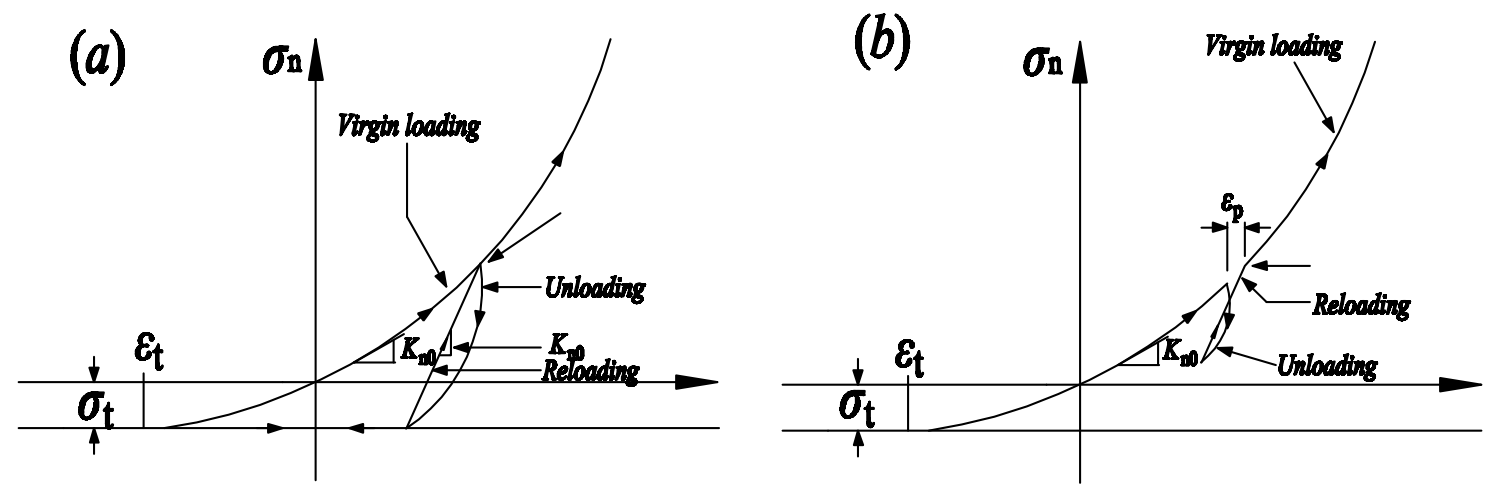

Fig. (4). Schematic of stress-strain response for normal behavior: (a) Virgin loading and unloading with tensile stress condition; (b) Partial loading [31]. 
After conducting a series of tests on the interface between coarse Hostun sand and rough steel in a direct shear box and the corresponding triaxial shear test on the sand, Boulon (1990) [33] modeled the interface behavior using elasto-plastic and rate type law. The endeavor to use the elasto-plastic strain hardening model was done by analyzing all the equations and determining of parameters by the test data. Then the rate-type law, which was a non-linear relationship between loading and response in an incremental way [34], was used in the analysis. Comparison between the results showed that the elasto-plastic model was simpler, characterized by fewer parameters but unable to model the final part of the loading process when loss of strength happened, while the rate-type law was able to predict the postpeak behavior but linked to a wider set of parameters and the integration step should be chosen carefully.

The "hierarchical approach" of modeling is a very important and effective idea in the development of elastoplastic model. The plasticity theory possesses the capability to model many essential material characteristics. But to cover a wide variety of material behaviors under diverse loading conditions tends to be either so general or too complicated to be of practical use. Therefore, it's important that a constitutive model being developed in a "modular way", which means adding a feature once a time and propagate the model little by little to make it efficient in modeling simple conditions and effective in a general range. The idea was first used by Fishman and Desai (1987) [35] in the development of constitutive model for rock joints. Navayogarajah (1990) [36] adopted this idea to develop an elasto-plastic constitutive model for the interface. The mathematical representative of the interface was first introduced, followed by including the static and cyclic behaviors. Then important functions in the model were defined and specified for monotonic and cyclic loading. Thereafter, evaluation and verification of parameters were done. Finally finite element method for interaction problems and application of the developed interface model for the boundary value problems were shown. Navayogarajah (1992) [37] continued to enrich the model by verifying it with simple shear test results on sand-steel and sand-concrete interfaces. The whole process of developing the interface model is a very good reference to further studies. Fakharian (1996) [3] also used the model to predict the abundant results of his static and cyclic shear tests on the sand-steel interface as stated previously, which proved the effectiveness of the model.

Other researches on the elasto-plastic constitutive model of the interface include the works by Gennaro et al. (2002) [38], Tabatabaei et al. (2010) [39] and Zhao et al. (2013) [40]. They followed the framework of plasticity commonly used in soils to define the hardening law and flow rule of mechanical behaviors of interface. Verifications for the models were done by comparisons with the test results.

Desai et al. (2005) [17] developed a constitutive model for sand-concrete interfaces using the Disturbed State Concept (DSC). This work was unique because cyclic tests and modeling of saturated sand interfaces and identification of liquefaction had not been reported in the past. It was an important endeavor also because that under dynamic loads, the responses of soil, including deformation and liquefaction, is an identical point in analyzing the whole structure-soil interaction system. And such responses are strongly influenced by the behavior of interface between saturated soil and structures. The interface zone was assumed to be composed of relative intact (RI) and fully adjusted (FA) states. The interface element may start with the complete RI state and gradually transformed to FA state. The disturbance acted as a coupling mechanism that connected the RI and FA states. The DSC was given in detail by Desai (2000) [41]. The determination of parameters and validation of the model were done, and the liquefaction identification was analyzed in detail. It was proved to be a realistic model for the stressdeformation and liquefaction response of the interface under dynamic loads.

Based on the direct shear test results [7], $\mathrm{Hu}$ and $\mathrm{Pu}$ (2003) [42] further developed a constitutive model in the framework of damage plasticity. The formation of the shear zone was regarded as the evolution from intact state to critical state. The stress and strain of the interface were considered as a linear combination of the two states. The functions for the two states, damage functions, stress-strain relationship and determination of parameters were stated in detail. Finally, the implementation of the interface element and its applications to a soil-structure interaction problem were showed to prove the strong ability of the model in predicting interface behaviors.

Liu et al. (2006) [43] compared the similarities between behaviors of soil and interfaces, and then developed a constitutive model based on the concept of critical state soil mechanics (CSSM). The ability of the model to predict the strain hardening, softening, normal dilatancy and stress-path dependency properties of sandy soil-structure interface during shearing was verified by comparison with the available test data by different researchers. A unification of the interface behavior with various roughness was also successful attempted. Then a more sophisticated model was proposed by Liu and his co-workers (2008) [44] to include cyclic loading and particle breakage, which was assumed to be related to the energy consumption during cyclic loading. The dependency of interface behavior on stress path and cyclic degradation can be successfully described by the proposed model.

By finishing the tests mentioned previously, Zhang and Zhang (2005) [45] proposed a unified constitutive model for the coarse-grained soil-structure interface on the basis of elasto-plasticity damage theory. The total plastic deformation was divided into one part caused by shear loads and another caused by normal loads. Thus two yield surfaces were introduced in the constitutive model. The concept of plastic damage was adopted to describe the shear deformation in shear loading. A prediction of the proposed model on the test results showed a good agreement. Hou (2008) [12] and Feng (2012) [13] also established their own constitutive model on the basis of plasticity theory. The constitutive models were based on the mechanical laws observed in the tests, which 
include strength law, shear law, dilatancy law, compressive law and evolution law (the changes of mechanical properties and physical state at interface). The constitutive models had been verified by comparing their predictions with the test results. The elasto-plastic model may be the most precise in theoretical point of view, but the large number of parameters should be selected with caution.

\section{MODELLING OF INTERFACES BASED ON DISCRETE ELEMENT METHOD (DEM)}

The granular materials are composed of large quantity of particles. The discontinuity of particles with a wide range of dimension order from millimeter to meter makes the properties of materials quite different from the continuum. As a result, more attentions should be focused on the properties of separate particles and different characteristics when assembled as a whole, i.e. the motions and interactions of particles. Cundall first proposed the Discrete Element Method (DEM) for this special purpose in 1979 [46]. From then on, many researchers have devoted their efforts to this prospecting field and the theory had been developing rapidly. Adopting DEM to modeling the behavior of interfaces between structure and granular materials is obviously a good idea. For the motion and interaction of particles, together with the shear zone development at the interface can be

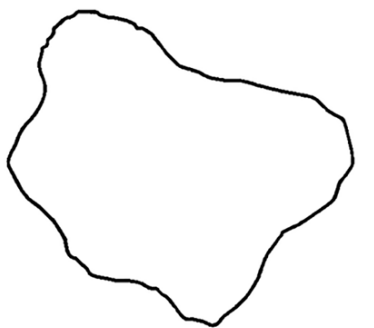

$\underline{\mathbf{A}}$

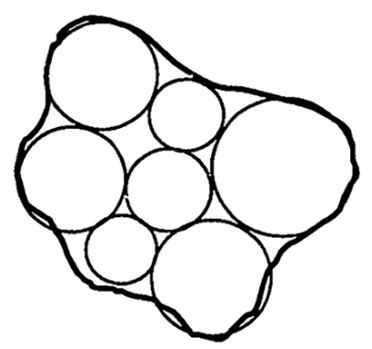

C monitored and analyzed directly, thus the inner principles and causes of the interface behaviors can be understood. Here are the main studies on the interface using DEM.

Jensen (1998) [47] developed the numerical methods to understand the micromechanical behavior of the particulate media-structure system by DEM in his doctoral dissertation. A DEM code called TRUBAL, which was developed by Cundall and Strack (1979) [46, 48], was used to simulate the shearing between rigid plate and particulate materials. The code is a realization of DEM in two-dimensional space, so the particles were represented by discs. The concept of "cluster", which was an assembly of several particles with different diameters as shown in Fig. (5), was generated by the code to model the irregular shapes of real granulate media. The structure part of the interface was simulated with "wall logic" in the code. A wall is a rigid plane that can translate, rotate and interact with particles. In order to model the roughness of the interface, the "sawtooth" shape with different amplitude and period was used to construct the wall to interact with the clusters. The model was shown in Fig. (6). Then a two-dimensional shear test was simulated using this method. The parameters varied in the simulation were clustered particles versus non-clustered particles, the roughness of the shearing structure surface and the magnitude of the applied normal force. And four basic

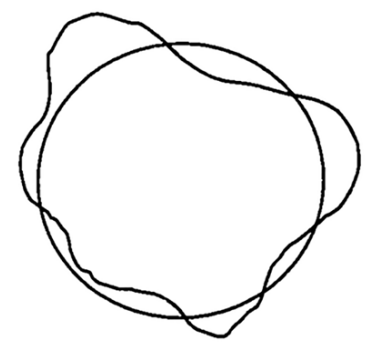

B

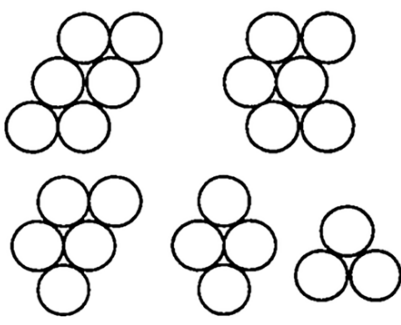

$\underline{\mathbf{D}}$

Fig. (5). (A) Outline of sand particles. (B) DEM disc element superimposed over sand particle. (C) DEM particles are joined together rigidly to form a "cluster", which closely resembles the actual particle. (D) Possible "cluster" combinations [47].

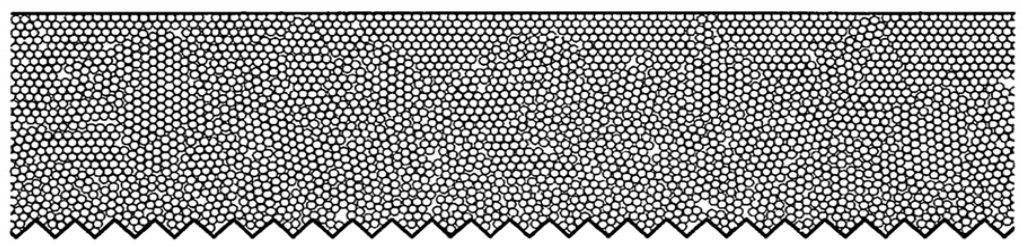

Fig. (6). Model of interface between granulate materials and structure [47]. 
measurements were extracted from the simulation, i.e.: 1) the shear force when the sawtooth surface moves; 2) the normal displacement of the top wall; 3) the particle displacements due to shearing; 4) the rotation of particles. Results showed that the overall behavior of the mass was qualitatively similar to those observed in experiments on sand-structure interfaces. So the modelling method was effective and could be extended for further parametric studies.

Then a detailed study of the effects of particle shapes on the DEM simulation was carried out. Eight types of clusters were generated to get different void ratio of particle assemblies. Broadly accepted methods were used to quantify geometric particle shapes to get the angularity and roughness index of the interface. The basic conclusions on the influence of void ratio, angularity of particles and roughness of the interface were reported.

Furthermore, an enhancement to the DEM that effectively simulated the damage in the granular materialstructure interface was presented. This was realized by utilizing the advantage of DEM of monitoring particles directly. Grain crushing could be modeled by the breakage of clusters into smaller particles. A damage criterion based on particles accumulating work from frictional sliding was implemented. Numerical ring shear tests were performed to demonstrate the effectiveness of this method. The results matched well with concepts and experiment data. Finally, a micromechanical constitutive model for granular materialstructure interface was proposed. The model was based on a two-dimensional contact problem and plasticity theory. An interface zone was characterized as a thin layer composed of particles which undergo large relative displacements with respect to the particle mass. The particles in the interface zone were then taken out to be analyzed separately and a new ratio $\beta$ was introduced to modify the slip function between particles. This modification enables the model to simulate the interface behavior in a micromechanical way. The predictions by the model, the physical test results and DEM numerical simulation results showed good agreement with each other, which proved the effectiveness of the model.

The research by Jensen was of great importance for offering detailed meso-scale monitoring results of interface behaviors. However, improvements are still necessary for his study was based on two-dimensional problems. The extension of this problem to three-dimensional space will provide us with more realistic results and more sophisticated constitutive relations.

Frost (2002) [4] conducted numerical shear tests using similar method with Jensen to study the influence of surface roughness and hardness on the interface behavior, mainly the peak friction angle. The results matched with his shear tests, which enabled him to analyze the interface behavior in particulate level and include more factors

Wang et al. (2007) [49] simulated the direct shear test using the DEM code PFC2D (a developed version of TRUBAL). Spherical particles were used to represent granulates and different surface roughness were introduced.
A new strain calculation method was proposed to account for the rotation of particles in the shear band. The comparison between calculation results, simulation results and test results matched well with each other. The advantage of DEM in monitoring particle movement was clearly shown in this study. By monitoring the motion of vertical columns of particles, the development and orientation of shear band could be shown. It was concluded that the shear band was in a mound shape in the shearing process and finally had a maximum thickness of $8 \sim 10$ median diameter of particles. The profound effect of rough boundary on the shear banding behavior was discussed in detail.

\section{CONCLUSION}

A review of literatures on the granular material-structural component interfaces has been taken. Main conclusions are listed as follows.

1. The shear stress versus tangential displacement relation of the interface is mostly affected by the inherent properties of interacting assembly and entity. Main influential factors for the friction angle of interface are mean diameter of particles and roughness of structural component surface. A linear correlation can be draw between the friction angle of the interface and these two factors, as stated in reference [1].

2. The upper bound of the interface friction angle is the friction angle of the sand. In most cases, the maximum ratio of shear stress and normal stress is about 0.6 when a sudden increase of tangential displacement at the interface occurs, which is a sign of slipping.

3. The peak shear stress at the interface is strongly influenced by the normal stress. The envelope of shear stress versus tangential displacement plots under cyclic loading is about the same as the curve of monotonic loading. The loading rate has little effect on the peak shear stress.

4. Constitutive models developed under different frameworks based on continuum mechanics by different scholars are summarized. The fruitfulness of models offers us with multiple choices in dealing with different problems. Among different types of constitutive relations, the inelastic model may be the most practical one for its clear physical meaning, sound experiment basis and simple parameters.

5. Particle movement, thickness of the shear zone are expected to affect interface behavior strongly. What's more, particle breakage and energy consumption in the area with large displacement are also not clear. So more careful measurements should be done on particulate level of the interface when being loaded in tangential direction. Such technologies are still not sophisticated.

6. DEM is a good numerical way to simulate the behaviors of granular materials. But simulations should be further extended to 3D level to get more persuasive conclusions on the interface properties. The developing mechanism of shear zone in loading process can also be verified by this. 
7. A more generalized constitutive model, which is able to describe the behavior of granular material-structure interface in multi directions and multi dimension levels is necessary. It should be developed by detailed experiments under multi-directional loading and with the assistant of numerical methods such as DEM simulation.

\section{CONFLICT OF INTEREST}

The authors confirm that this article content has no conflict of interest.

\section{ACKNOWLEDGEMENTS}

Project (2011ZA05) Supported by State Key Laboratory of Subtropical Building Science in South China University of Technology, China.

\section{REFERENCES}

[1] U. Morimichi, and K. Hideaki, "Frictional resistance at yield bssetween dry sand and mild steel," Soils and Foundations, vol. 26, no. 4, pp. 139-149, 1986.

[2] J. Tejchman, and W. Wu, "Experimental and numerical study of sand-steel interfaces," International Journal for Numerical and Analytical Methods in Geomechanics, vol. 19, pp. 513-536, 1995.

[3] K. Fakharian, "Three-dimensional Monotonic and Cyclic Behaviour of Sand-steel Interfaces: Testing and Modelling ", PhD thesis, University of Ottawa, Canada, 1996.

[4] J.D. Frost, J.T. DeJong, and M. Recalde, "Shear failure behavior of granular-continuum interfaces," Engineering Fracture Mechanics, vol. 69 , pp. 2029-2048, 2002.

[5] D. Porcino, V. Fioravante, V.N. Ghionna, and S. Pedroni, "Interface behavior of sands from constant normal stiffness direct shear tests," Geotechnical Testing Journal, vol. 26, no. 3, pp. 289301, 2003

[6] C.S. Desai, E.C. Drumm, and M.M. Zaman, "Cyclic testing and modeling of interfaces," Journal of Geotechnical Engineering, vol. 111 , no. 6, pp. 793-815, 1985.

[7] L.M. Hu, and J.L. Pu, "Experimental study on mechanical characteristics of soil-structure interface," Chinese Journal of Geotechnical Engineering, vol. 23, no. 4, pp. 431-435, 2001.

[8] G. Zhang, and J.M. Zhang, "Development and application of cyclic shear apparatus for soil-structure Interface," Chinese Journal of Geotechnical Engineering, vol. 25, no. 2, pp. 149-153, 2003.

[9] G. Zhang, and J.M. Zhang, "Experimental study on monotonic behavior of interface between soil and structure," Chinese Journal of Geotechnical Engineering, vol. 26, no. 1, pp. 21-25, 2004.

[10] G. Zhang, and J.M. Zhang, "Experimental study on cyclic behavior of interface between soil and structure," Chinese Journal of Geotechnical Engineering, vol. 26, no. 2, pp. 254-258, 2004.

[11] G. Zhang, and J.M. Zhang, "Monotonic and cyclic constitutive law of interface between structure and coarse grained soil," Chinese Journal of Geotechnical Engineering, vol. 27, no. 5, pp. 516-520, 2005.

[12] W.J. Hou, "Research on Monotonic and Cyclic Behavior and Constitutive Model of Three-dimensional Soil-Structure Interface", $\mathrm{PhD}$ thesis, Tsinghua University, Beijing, 2008.

[13] D.K. Feng, "Three-dimensional Constitutive Laws, Mechanism and Model of Gravel-structure Interfaces", $\mathrm{PhD}$ thesis, Tsinghua University, Beijing, 2012.

[14] K. Peng, J.G. Zhu, D. Zhang, and X.Y. Wu, "Study of mechanical behaviors of interface between coarse-grained soil and concrete by simple shear test," Chinese Journal of Rock Mechanics and Engineering, vol. 29, no. 9, pp. 1893-1900, 2010.

[15] J.G. Zhu, R.R. Shakir, Y.L. Yang, and K. Peng, "Comparison of behaviors of soil-concrete interface from ring-shear and simple shear tests," Rock and Soil Mechanics, vol. 32, no. 3, pp. 692-696, 2011.

[16] C.S. Desai, and D.B. Rigby, "Cyclic interface and joint shear device including pore pressure effects," Journal of Geotechnical and Geoenvironmental Engineering, vol. 123, no. 6, pp. 568-579, 1997.

[17] C.S. Desai, S.K. Pradhan, and D. Cohen, "Cyclic testing and constitutive modeling of saturated sand - concrete interfaces using the disturbed state concept," International Journal of Geomechanics, vol. 5, no. 4, pp. 286-294, 2005.

[18] Q. Yang, and Y.S. Xue, "Horizontal anti-slide field test between RC plate and crushed stone cushion," Geotechnical Investigation \& Surveying, vol. 27, no. 6, pp. 5-8, 1999.

[19] J.H. Qian, "The investigation of resisting slip text between the concrete slab and the groundsill," Journal of Anhui Technical College of Water Resources and Hydroelectric Power, vol. 2, no. 1 , pp. 20-23, 2002.

[20] Z.W. Liu, "Field test to determine the fictional coefficient between ground soil and sand or gravel cushion," West-China Exploration Engineering, vol. 22, no. 11, pp. 15-17, 2010.

[21] R.E. Goodman, R.L. Taylor, and T.L. Brekke, "A model for the mechanics of jointed rock," Journal of the Soil Mechanics and Foundations Division, vol. 94, no. 3, pp. 637-660, 1968.

[22] O.C. Zienkiewia, B. Best, C. Dullage and K.G. Stagg, "Analysis of nonlinear problems with particular reference to jointed rock systems," In: $2^{\text {nd }}$ International Conference Society of Rock Mechanics, Belgrade: Yugoslavia, 1970.

[23] J. Ghaboussi, E.L. Wilson, and J. Isenberg, "Finite element for rock joints and interfaces," Journal of Soil Mechnanics. and Foundation Division, ASCE, vol. 99, no. 10, pp. 849-862, 1973.

[24] M.G. Katona, "CANDE-a modern approach for the structural design and analysis of buried culverts", Tech. Report FltwA-RD. 77J, Federal Highway Administration: Washington, D.C., 1976.

[25] M.G. Katona, "A simple contact-friction interface element with applications to buried culvert," In: Proceeding of Symposium on Implication of Computer Procedures and Stress-Strain Laws in Geotechnical Engineering, Chicago, Illinois, 1981.

[26] L.R. Herrmann, "Finite element analysis of contact problems," Journal of Engineering Mechanics Divison, ASCE, vol. 104, pp. 1043-1057, 1978.

[27] C.S. Desai, M.M. Zaman, J.G. Lightner, and H.G. Siriwardane, "Thin-layer element for interfaces and joints," International Journal for Numerical and Analytical Methods in Geomechanics, vol. 8, no. 1, pp. 19-43, 1984.

[28] M.M. Zaman, C.S. Desai, and E.C. Drumm, "Interface model for dynamic soil-structure interaction," Journal of Geotechnical Engineering, vol. 110, no. 9, pp. 1257-1273, 1984.

[29] K. G. Sharma, and C. S. Desai, "Analysis and implementation of thin-layer element for interfaces and joints," Journal of Engineering Mechanics, vol. 118, no. 12, pp. 2442-2462, 1992.

[30] G.W. Clough, and J.M. Duncan, "Finite element analysis of retaining wall behavior," Journal of the Soil Mechanics and Foundations Division, ASCE, vol. 97, pp. 1657-1672, 1971.

[31] C.S. Desai, and B.K. Nagaraj, "Modeling for cyclic normal and shear behavior of interfaces," Journal of Engineering Mechanics, vol. 114 , no. 7, pp. 1198-1217, 1988.

[32] Z. Chen, and H. L. Schreyer, "Simulation of soil-concrete interfaces with nonlocal constitutive models," Journal of Engineering Mechanics, vol. 113, no. 11, pp. 1665-1677, 1987.

[33] M. Boulon, and R. Nova, "Modelling of soil-structure interface behaviour a comparison between elastoplastic and rate type laws," Computers and Geotechnics, vol. 9, pp. 21-46, Sep. 1990.

[34] M. Boulon, "Basic features of soil structure interface behaviour," Computers and Geotechnics, vol. 7, pp. 115-131, Jul. 1989.

[35] K.L. Fishman, and C.S. Desai, "A constitutive model for hardening behavior of rock joints," In: $2^{\text {nd }}$ International Conference on Constitutive Laws for Engineering Materials, Tucson: Arizona, 1987.

[36] N. Navayogarajah, "Constitutive Modeling of Static and Cyclic Behavior of Interfaces and Implementation in Boundary Value Problems", PhD thesis, The University of Arizona, USA, 1990.

[37] N. Navayogarajah, C. S. Desai, and P. D. Kiousis, "Hierarchical single-surface model for static and cyclic behavior of interfaces," Journal of Engineering Mechanics, vol. 118, no. 5, pp. 990-1011, 1992.

[38] V.D. Gennaro, and R. Frank, "Elasto-plastic analysis of the interface behaviour between granular media and structure," Computers and Geotechnics, vol. 29, no. 7, pp. 547-572, 2002.

[39] A. Tabatabaei, A.M. Halabian, K. Barkhordari, and S.H. Hashemolhosseini, "A simple constitutive model of soilstructure 
interface using soil plasticity," In: $5^{\text {th }}$ National Congress on Civil Engineering, Mashhad: Iran, 2010.

[40] C. Zhao, C.F. Zhao, and H. Gong, "Elastoplastical analysis of the interface between clay and concrete incorporating the effect of the normal stress history," Journal of Applied Mathematics, vol. 2013, pp.1-12, 2013.

[41] C.S. Desai, "Evaluation of liquefaction using disturbed state and energy approaches," Journal of Geotechnical and Geoenvironmental Engineering, vol. 126, no. 7, pp. 618-631, 2000.

[42] L.M. Hu, and J.L. Pu, "Application of damage model for soilstructure interface," Computers and Geotechnics, vol. 30, pp. 165$183,2003$.

[43] H.B. Liu, and H.I. Ling, "Constitutive description of interface behavior including cyclic loading and particle breakage within the framework of critical state soil mechanics," International Journal for Numerical and Analytical Methods in Geomechanics, vol. 32, pp. 1495-1514, 2008.

[44] H.B. Liu, E.X. Song, and H.I. Ling, "Constitutive modeling of soilstructure interface through the concept of critical state soil mechanics," Mechanics Research Communications, vol. 33, pp. 515-531, 2006.

[45] G. Zhang, and J.M. Zhang, "Unified modeling of soil-structure interface and its test confirmation," Chinese Journal of Geotechnical Engineering, vol. 27, no. 10, pp. 1175-1179, 2005.

[46] P.A. Cundall, and O.D.L. Strack, "A discrete numerical model for granular assemblies," Geotechnique, vol. 29, no. 1, pp. 47-65, 1979.

[47] R.P. Jensen, "Numerical and Analytical Modeling of the Microstruc-tural Behavior of a Particulate Media-structure Interfacec", $\mathrm{PhD}$ thesis, University of Wisconsin-Madison, America, 1998.

[48] P.A. Cundall, and O.D.L. Strack, "The Distinct Element Method as a Tool for Research in Granular Media PART II", Tech. Report ENG76-20711, NSF, 1979.

[49] J.F. Wang, M.S. Gutierrez and J.E. Dove, "Numerical studies of shear banding in interface shear tests using a new strain calculation method," International Journal for Numerical and Analytical Methods in Geomechanics, vol. 31, pp. 1349-1366, 2007.

(C) Li et al.; Licensee Bentham Open.

This is an open access article licensed under the terms of the Creative Commons Attribution Non-Commercial License (http://creativecommons.org/licenses/ by-nc/3.0/) which permits unrestricted, non-commercial use, distribution and reproduction in any medium, provided the work is properly cited. 